\title{
Tackling gynecological health problems in adolescent girls of rural India: need of the hour
}

\author{
Barkha A. Bafna*, Amit N. Bafna
}

Department of Obstetrics and Gynecology, Bafna Hospital, Dhule, Maharashtra, India

Received: 31 March 2021

Accepted: 01 May 2021

\section{*Correspondence:}

Dr. Barkha A. Bafna,

E-mail: barkhajainbafna@yahoo.com

Copyright: (c) the author(s), publisher and licensee Medip Academy. This is an open-access article distributed under the terms of the Creative Commons Attribution Non-Commercial License, which permits unrestricted non-commercial use, distribution, and reproduction in any medium, provided the original work is properly cited.

\begin{abstract}
Background: Adolescence is a transient and dynamic period characterised by several changes in the child's body and mind. Onset of menarche is major physiological milestone in adolescent girls which is often associated with menstrual irregularities and other hormonal events. Aim of the present study was to evaluate the profile of adolescent girls attending the outpatient clinic.

Methods: This hospital based cross-sectional, prospective, observational study was conducted at Bafna hospital from January 2019 to December 2020. We analysed 220 consecutive adolescent girls with gynaecological health issues. The data was collected and analysed using pre-designed questionnaire.

Results: Menstrual disorders (64.5\%) were most common followed by teenage pregnancies (20.9\%). Other complaints included vulvar disorders, breast diseases, genital trauma, hirsuitism, UTI and psychological problems. Anemia $(28.1 \%)$ and PCOS (30.9\%) were also diagnosed. Hormonal treatment was offered to $59.5 \%$ girls whereas surgical intervention done in $4 \%$ for various indications.

Conclusions: Menstrual disorders, teenage pregnancies, PCOS and anemia were the most common issues seen. Adolescent gynaecological problems are unique and specific regarding presentation, diagnosis and treatment options. It is important to tackle them on top priority due to its impact on future reproductive health.
\end{abstract}

Keywords: Adolescence, Menstrual disorders, Anemia, Polycystic ovarian syndrome

\section{INTRODUCTION}

Adolescence is a transient, dynamic period of life between childhood and adulthood characterized by several changes in the body and mind of a child. ${ }^{1}$ World Health Organisation defines adolescent as young people aged 10-19 years of age. Adolescents constitute over $21.4 \%$ of population in India and represents almost onefifth of the world's population.

Early adolescence comprises the 10-14 years age group. ${ }^{2}$ It is characterized by a spurt in physical, endocrinal, emotional and mental growth leading to excitement while undergoing transformation. Late adolescence encompasses the age group 15-19 years. ${ }^{2}$ The major physical changes have occurred although the mind is still developing. They are psychologically labile and vulnerable.

Increased demand of an adolescent body, nutritional deprivation, onset of menarche may aggravate anemia and its effects. On the other hand, over-nutrition, lack of exercise, ignorance can lead to childhood obesity with predisposition to increased future risk of metabolic disorders like diabetes mellitus, hypertension and subfertility. Various gynaecological problems identified are menstrual irregularities, sexual abuse, pregnancy related problems, endocrinopathies. Adolescence provides a window to identify, rectify and prevent future health problems. Embarrassment about discussing menstruation, 
fear of disease and ignorance about available services may lead to delayed presentation.

\section{METHODS}

Current study was a hospital based cross-sectional, prospective, observational study conducted at Bafna hospital from January 2019 to December 2020. We analysed 220 consecutive adolescent girls presenting to the clinic with gynaecological health issues. The data was collected and analysed using pre-designed questionnaire with respect to age distribution, menstrual problems, gynecologial disorders, investigations and treatment required.

\section{Inclusion criteria}

Inclusion criterion for current study was all girls of age group 10-19 years attending the outpatient department.

\section{Exclusion criteria}

Exclusion criterion for current study was girls less than 10 years and more than 19 years, girls not willing to participate.

Detailed general and systemic examination was done including BMI, pallor, hirsuitism, examination of breast, secondary sexual characters, thyroid, abdomen, external genital along with per vaginal/rectal examination if required. Investigations included hemogram, coagulation profile, thyroid function tests, hormone assays, tumour markers, karyotyping, USG, MRI etc. as and when indicated. The data was analysed and expressed in tables and graphs using frequency and percentages.

\section{RESULTS}

All 220 adolescent girls were divided into: early and late adolescent age groups. Most girls 70\% (154) belonged to the late adolescent age group (Figure 1).

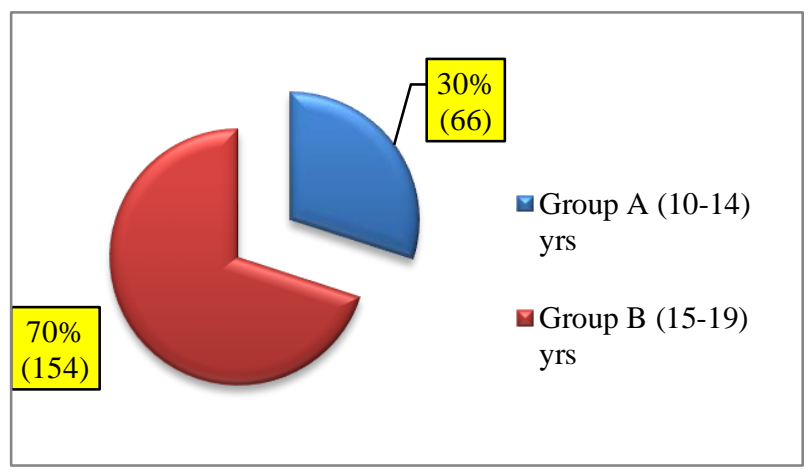

Figure 1: Age distribution.

The average age of menarche was between 10-13 years in most girls 62.27\% (148) (Figure 2). Maximum girls had a normal BMI, however 20\% (44) were underweight
(Figure 3). Educational status was analysed and found that $64.54 \%$ (142) completed secondary education and above. It was found that $8.18 \%$ (18) never went to school and $20 \%$ (44) were school dropouts (Figure 4). About $23.18 \%$ (51) adolescent girls were married (Figure 5).

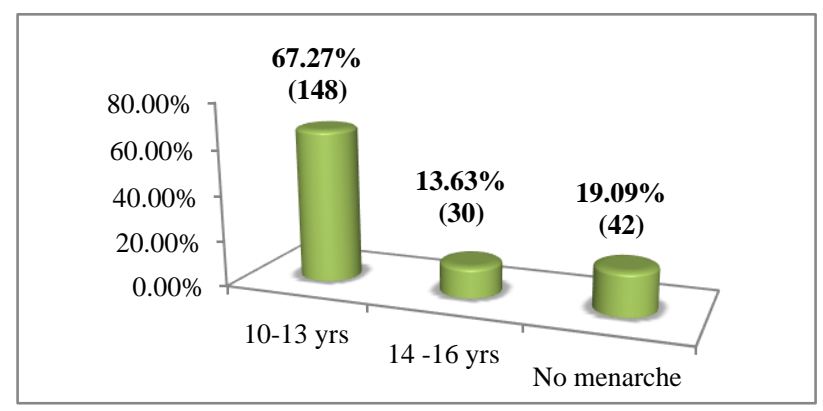

Figure 2: Average age of menarche.

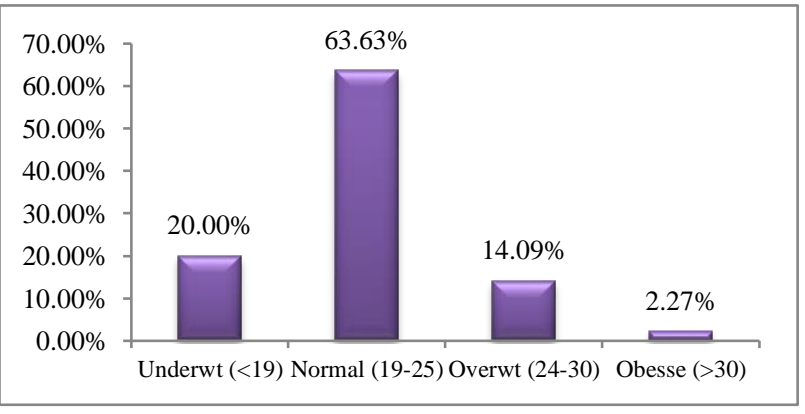

Figure 3: BMI of study participants.

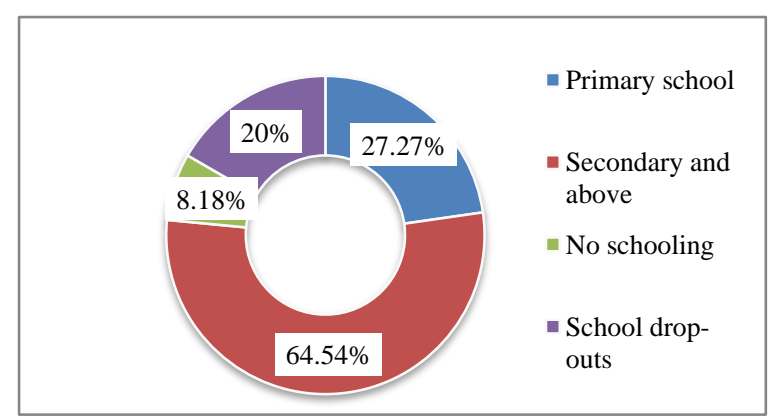

Figure 4: Educational status of the participants.

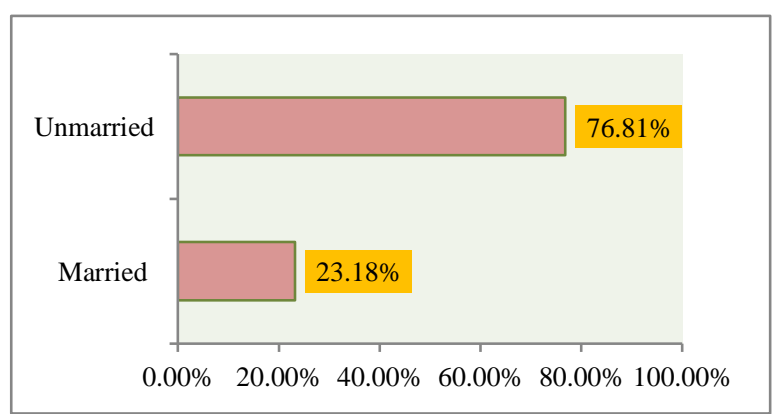

Figure 5: Marital status of participants.

Menstrual disorder was the single most common problem seen in $64.5 \%$, followed by teenage pregnancies in $20.9 \%$ 
(Figure 6). Oligomenorrhea including secondary amenorrhea was most common menstrual dysfunction seen in $47.3 \%$ girls followed by menorrhagia and polymenorrhea in $23.6 \%$ girls. Primary amenorrhea was noted in $4 \%$ adolescent girls. It was seen that early adolescent girls had menorrhagia/polymenorrhea followed by oligomenorrhea/secondary amenorrhea however, reverse pattern was seen in late adolescent group (Figure 7). This shows that puberty menorrhagia is common symptom in early adolescent group and PCOS is more common in late adolescent group.

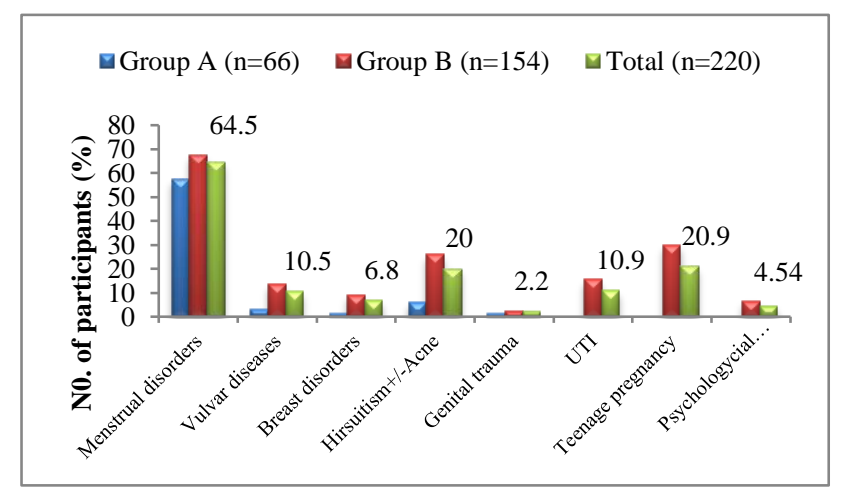

Figure 6: Distribution of gynecological problems.

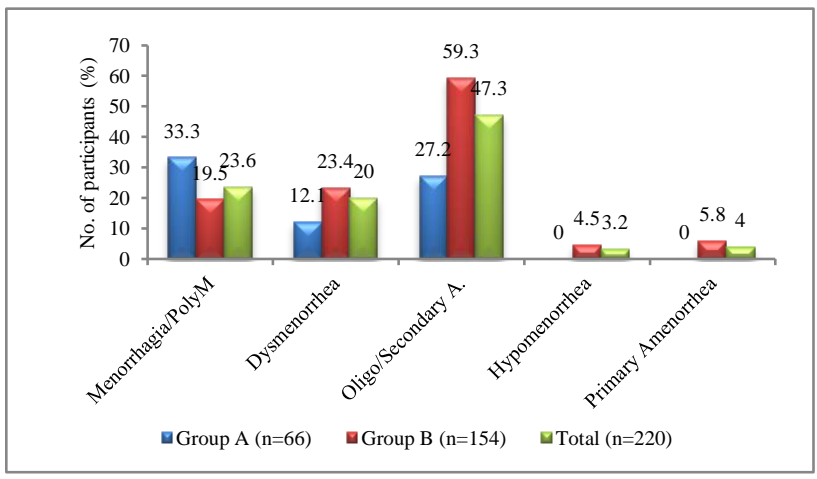

Figure 7: Pattern of menstrual disorders.

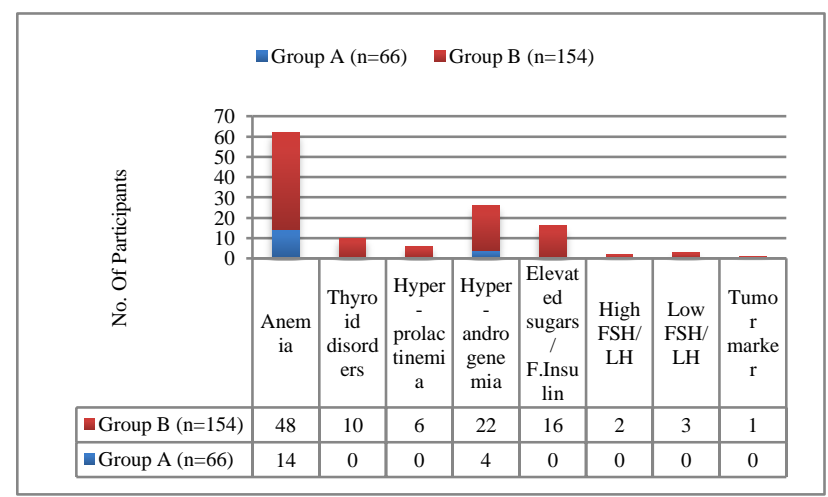

Figure 8: Investigations.

Anemia was detected in $28.1 \%$ (62), hyperadrogenemia in $11.8 \%$ (26) and thyroid dysfunction in $4.5 \%$ (10) girls. Low FSH/LH seen in 3 girls (Figure 8). The various ultrasound findings seen are elaborated in (Figure 9). PCOS was most common finding in over one-third adolescent girls out of which $21.1 \%$ were early adolescent group and $35 \%$ were late adolescent group.

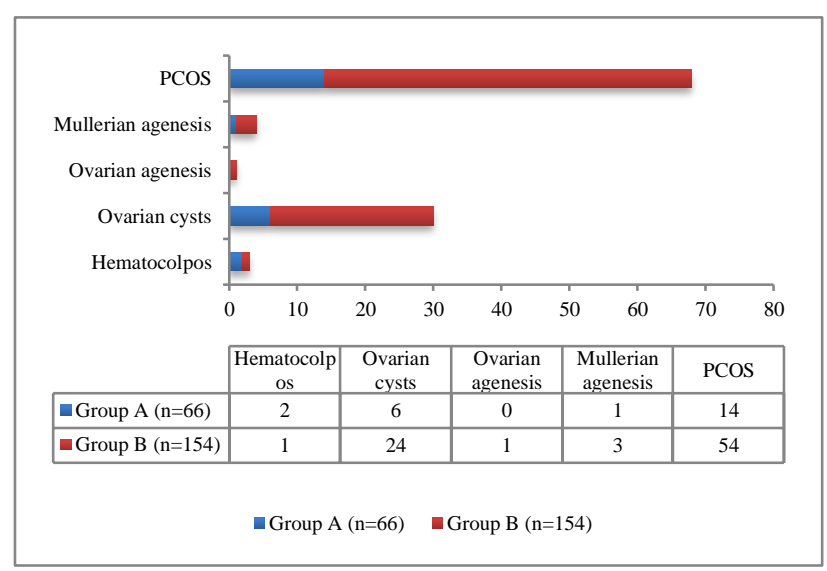

Figure 9: Ultrasound findings.

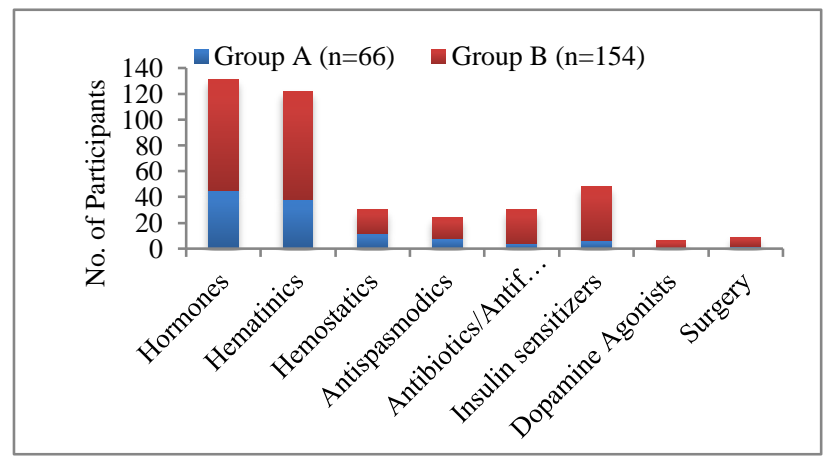

Figure 10: Treatment modalities.

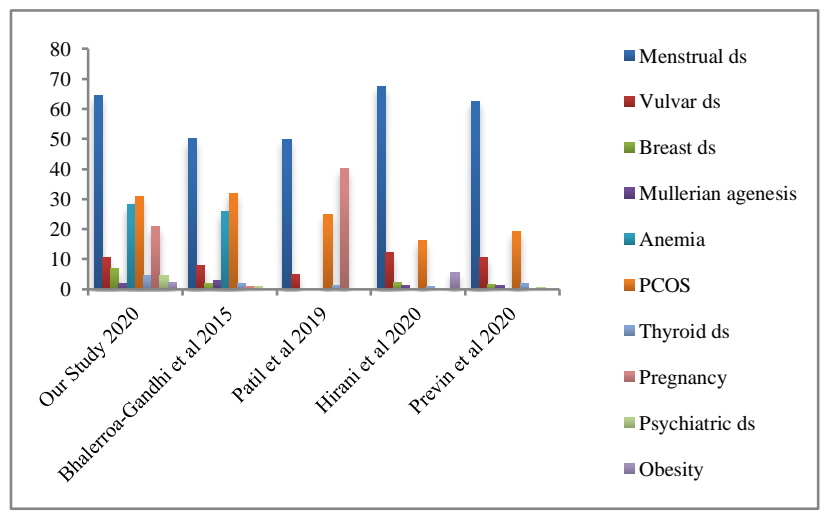

Figure 11: Comparison of studies.

Various treatment modalities were used to treat the adolescent girls as shown in (Figure 10). Hormone therapy was offered to $59.5 \%$ (131). Haematinics were given to $54.5 \%$ girls to supplement the increasing demand for growth/pregnancy, loss due to menorrhagia and treat nutritional anemia. Surgery was required in 9 girls (4\%); 3 cases of hymen atresia, 2 cases of fibroadenoma of breast (size $>5 \mathrm{~cm}$ ) and 4 girls underwent laproscopy for benign ovarian masses torsion 
of ovarian cyst, large par-ovarian cyst, dermoid cyst and mucinous cystadenoma. All surgical masses were confirmed by histopathology.

\section{DISCUSSION}

Current study when compared with similar other Indian studies demonstrated similar trends in prevalence of gynaecological disorders in adolescent girls (Figure 11). ${ }^{6}$ Menstrual disorders $(64.5 \%)$ were found to be the most common gynaecological disorder in our study. Embarrassment about discussing menstruation and ignorance about available services may lead to delayed presentation.

Teenage pregnancies $(20.9 \%)$ and its vices continue to haunt the reproductive health of adolescent girls. Early marriages $(23.18 \%)$, lack of schooling $(8.18 \%)$, school drop-outs (20\%), lack of knowledge about safe-sex practices and gender inequality could be the major reasons behind this alarming situation. Anemia was another morbidity very prominently associated with young girls. Increase demand, poor nutrition, excessive menstrual loss, faulty eating habits make adolescent girls susceptible to anemia which has long lasting consequences on growth and development in later life..$^{7-9}$ On the other hand, changes in lifestyle, faulty eating habits and sedentary life has led to rapid increase in prevalence of PCOS, obesity and endocrinopathies. ${ }^{10}$ Vulvar disease, breast disorders, Mullerian agenesis and psychiatric disorders are some other problems seen in adolescent girls.

\section{CONCLUSION}

In current study, more than half of adolescent girls suffered from menstrual disorders. One-third had anemia and PCOS. Over one-fifth carried the burden of teenage pregnancies. Adolescent gynecology is an emerging speciality. There is an unmet need for specialized clinics to cater to the unique needs of the young girls. Adolescent girls should be dealt with affection, empathy and non- judgemental attitude with a promise of maintaining confidentiality. We must look upon adolescence as a window of opportunity to groom them into healthy women for healthier future generations to come.

Funding: No funding sources Conflict of interest: None declared

Ethical approval: The study was approved by the Institutional Ethics Committee

\section{REFERENCES}

1. Creatsas G. Adolescent gynecology and obstetrics. Eur J Obstet Gynecol Reprod Bio. 1995;58(2):107-9.

2. RCOG Greentop Guideline 29. Available at: https://www.rcog.org.uk/en/guidelines-researchservices/guidelines/gtg29/. Accessed on 20 January 2021.

3. Bhalerao-Gandhi A, Vaidiya R, Bandi F. Managing gynaecological problems in indian adolescent girls- a challenge of 21 st century. Obstet Gynecol Int J. 2015;3(1):70.

4. Patil SS, Mahanthshetty H, Supriya HM, Mahendra M. Gynecological problems of adolescent girls attending to rural tertiary care centre. Int $\mathrm{J}$ Reprod Contracept Obstet Gynecol. 2019;8:2627-30.

5. Hirani DG, Hirani M. Prevalence of various gynecological problems in adolescent girls 10-19 years of age attending outpatient Department at tertiary care institute of Bhuj, Kutch, Gujarat, India. J Obstetr Gynecol. 2020;6(2):51-6.

6. Pervin HH, Kazal RK, Parveen T. Fatema K, Chowdhury SA. Frequency and pattern of gynecological problems of adolescent girls attending outpatient department, department of obstetrics and gynecology, Bangabandhu Sheik Mujib Medical University, Bangladesh. Int J Reprod Contracept Obstet Gynecol. 2020;9:3931-5.

7. Adolescence- an age of opportunity. Available at: https://www.unicef.org/sowc2011/pdfs/SOWC-2011Main-Report_EN_02092011.pdf. Accessed on 20 January 2021.

8. Hemoglobin concentration for the diagnosis of anemia and assessment of severity. Available at: https://www.who.int/vmnis/indicators/haemoglobin/e n/. Accessed on 20 January 2021.

9. Adolescent nutrition- A review of situation in selected South East Asian countries. Available at: https://apps.who.int/iris/handle/10665/204764. Accessed on 20 January 2021.

10. Carmina E, Oberfield SE, Lobo RA. The diagnosis of polycystic ovary syndrome in adolescents. Am J Obstet Gynecol. 2010;203(3):e1-5.

Cite this article as: Bafna BA, Bafna AN. Tackling gynecological health problems in adolescent girls of rural India: need of the hour. Int J Reprod Contracept Obstet Gynecol 2021;10:2326-9. 